Abbreviated Key Title: Sch J Med Case Rep

ISSN 2347-9507 (Print) | ISSN 2347-6559 (Online)

Journal homepage: https://saspublishers.com/sjmcr/

\title{
Facial Paralysis Revealing Post-Traumatic Cholesteatoma: Case Report
}

\author{
N. Touiheme*, H. Attifi, M. Hmidi, I. Nakkabi, H. Belatik, K. Nadour, A. Boukhari
}

ENT and head and neck surgery, Military Hospital Moulay Ismail, Meknes, Morocco

DOI: $10.36347 /$ sjmcr.2020.v08i02.033

| Received: 17.02.2020 | Accepted: 24.02.2020 | Published: 25.02.2020

*Corresponding author: Touiheme Nabil

\section{Abstract}

Post-Traumatic cholesteatoma is a very rare entity. It occurs several years after the trauma to the temporal bone hence the difficulty of the diagnosis. We reported A case of posttraumatic cholesteatoma is presented that was revealed by a right facial nerve paralysis 10 years after the head trauma. Post-Traumatic cholesteatoma is revealed by repetitive otorrhea, or directly at the complication stage such as facial paralysis. Diagnosis is facilitated by imaging, especially the scanner. Treatment is based on surgery especially the wall up tympanoplaty. This case reveals the importance of prolonged monitoring of temporal bone trauma.

Keywords: Facial Paralysis; Traumatic; Cholesteatoma.

Copyright @ 2020: This is an open-access article distributed under the terms of the Creative Commons Attribution license which permits unrestricted use, distribution, and reproduction in any medium for non-commercial use (NonCommercial, or CC-BY-NC) provided the original author and source are credited.

\section{INTRODUCTION}

Cholesteatoma of the middle ear is a chronic ear infection described as dangerous because of the evolutionary risks and potentially serious complications. Post-traumatic cholesteatoma is recognized as a rare but late complication of various types of temporal bone damage. We report a case of post-traumatic cholesteatoma revealed by facial paralysis occurring several years after a head trauma.

\section{Case Report}

A 51 years old man, consulted for a progressive right facial paralysis evolving for two years. In his antecedents there is an accident on the public highway with trauma to the right temporomandibular region dating back more than 10 years. The examination, carried out on a patient in good general condition, found at inspection a complete peripheral facial paralysis grade $\mathrm{V}$ of House and Brakmann (Figure-1).

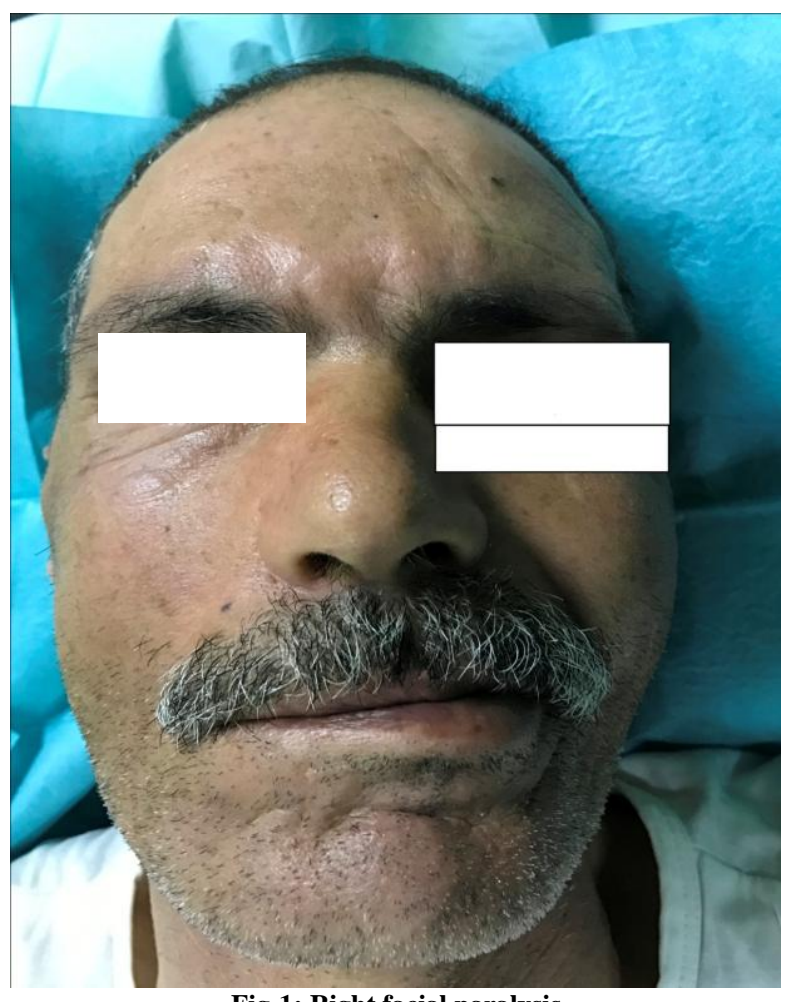

Fig-1: Right facial paralysis 
The otoscopy of both ears was normal, which must be behind the delay in diagnosis since the paralysis was considered to be at Bell palsy. The instrumental acoumetry was in favor of a deafness of transmission confirmed by the preliminary tonal audiometry with an auditory rinse of $40 \mathrm{Db}$. The stapedial reflex was absent on the affected side.

Faced with the persistence of facial paralysis, a tomodensitometry (CT) of the temporal bone was requested and which revealed a tissue filling arriving in contact with the second portion of the facial nerve (Figure-2).

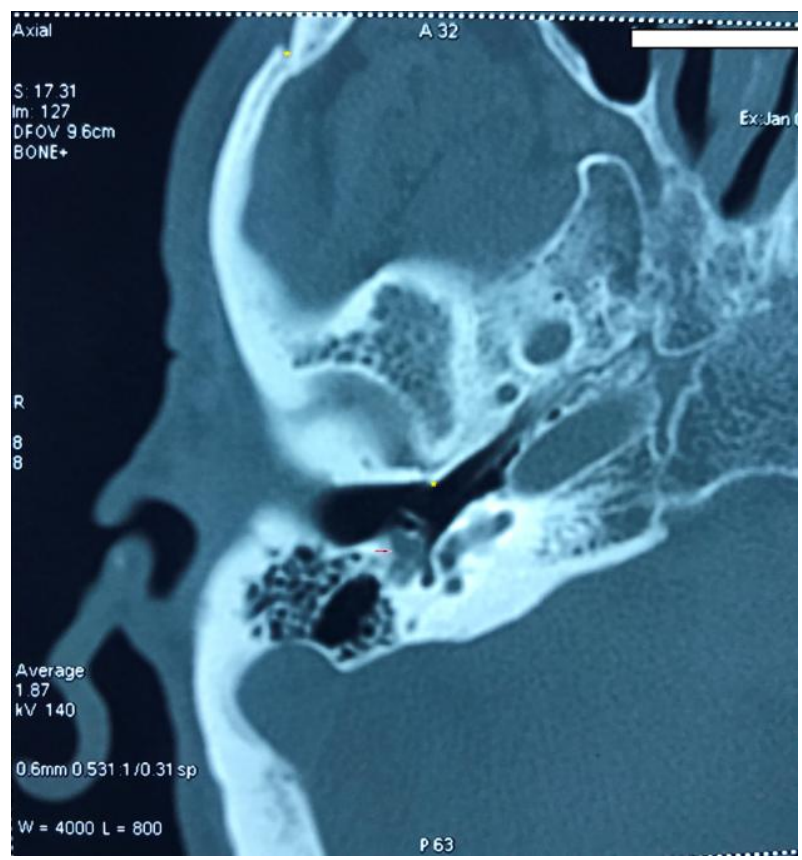

Fig-2: CT temporal bone, in axial section showing sequelae of trauma to the temporal bone (yellow star), and cholesteatoma on the path of the facial nerve (red arrow)

The EMG of the facial nerve objectified an intra-axial involvement with no response. The patient was scheduled for canal wall-up tympanoplasty, intraoperatively, we found a filling of the posterior region of the eardrum, concerning the second portion of the facial nerve and the initial part of the third. The postoperative courses were simple but no improvement of facial nerve function was noted after three years of monitoring

\section{DiSCUSSION}

Post-Traumatic cholesteatoma is an exceptional complication of fractures of the temporal bone which can remain asymptomatic for years, allowing it to develop gradually. The time interval between the temporal bone damage and the diagnosis of the posttraumatic cholesteatoma is very variable and may range from 1 to 25 years. In the majority of the cases reported in the literature, the interval was more than 10 years. In our case, the latent interval is 10 years [1-3].
Post-traumatic cholesteatoma can be located at the level of the middle ear, the external auditory canal or more rarely extend intra cranially [4].

The pathophysiology of post-traumatic cholesteatoma is still poorly understood, the most credible mechanism is the incarceration of epidermis in the fracture site [5]

In most cases, the evocative clinical signs of a cholestéatome are fetid otorrhea, otalgy, and hearing loss [1]. for our patient, it was the facial paralysis that was revealing.

The facial paralysis is a rare complication of cholestéatome with a frequency estimated at 1-2\% [1]. Generally, his installation is rapid during an infection but sometimes, it is progressive during an erosion of the facial canal [6]

The CT-scan currently occupies an essential place in the diagnosis of middle ear cholesteatoma because it can provide semiological arguments in favour of the positive diagnosis with tissue filling the middle ear cavities and signs of osteolysis, specify the extensions, and seek possible complications like a lysis of the tegmen tympani and/or antri, a labyrinthine fistula, or an erosion of the facial nerve canal, and also helps guide surgery [1, 4]. The MRI occupies the second place. However, it may provide additional information on the delineation and extension of cholestéatome and on potential complications [1]. The therapeutic management is surgical consisting primarily of a canal wall up which is indicated whenever possible or a canal wall down tympanoplasty with treatment of the complications if it is necessary $[1,4]$.

Post-Traumatic cholesteatoma also poses a forensic problem, concerning its imputability to the cranial trauma, especially that it occurs several years later, hence the importance of prolonged monitoring after trauma to the temporal bone [4].

\section{Conclusion}

Post-traumatic cholesteatoma is an exceptional complication of temporal bone trauma. Its diagnosis is made after several years of evolution, sometimes at the stage of complications that can compromise the functional and even vital prognosis, hence the need to regular monitoring of any patient with temporal bone trauma order an early diagnosis and lead to therapy as soon as possible.

\section{REFERENCES}

1. Chihani M, Aljalil A, Touati M, Bouaity B, Ammar H. Posttraumatic Cholesteatoma Complicated by a Facial Paralysis: A Case Report. Case reports in otolaryngology. 2012;2012. 
N. Touiheme et al, Sch J Med Case Rep, Feb., 2020; 8(2): 225-227

2. Naidoo L, Nanan A. Post-traumatic cholesteatoma... a rare occurrence. SA Journal of Radiology. 2008;12(2):46-9.

3. Brookes GB. Post-traumatic cholesteatoma. Clinical Otolaryngology \& Allied Sciences. 1983 Feb;8(1):31-8.

4. Hammami B, Mnejja M, Chakroun AM. Cholestéatome post-traumatique de l'oreille moyenne à propos d'un cas. Médecine du Maghreb, 2011; 188:18-20.

5. Holt JJ. Ear canal cholesteatoma. The Laryngoscope. 1992 Jun;102(6):608-13.

6. Smith JA, Danner CJ. Complications of chronic otitis media and cholesteatoma. Otolaryngologic Clinics of North America. 2006 Dec;39(6):123755. 